\title{
Correction to: Lewis Fry Richardson: His Intellectual Legacy and Influence in the Social Sciences
}

\author{
Nils Petter Gleditsch
}

\section{Correction to:}

N. P. Gleditsch (ed.), Lewis Fry Richardson: His Intellectual

Legacy and Influence in the Social Sciences, Pioneers

in Arts, Humanities, Science, Engineering,

Practice 27, https://doi.org/10.1007/978-3-030-31589-4_8

In the original version of the book, the following correction were incorporated: The name "Gregory D. Hess" has now been corrected to "George D. Hess" in the pages $70,83,98,111$ and 145 . The book and the chapters have been updated with the change.

\footnotetext{
The updated versions of these chapters can be found at https://doi.org/10.1007/978-3-030-31589-4_6 https://doi.org/10.1007/978-3-030-31589-4_7 https://doi.org/10.1007/978-3-030-31589-4_8 https://doi.org/10.1007/978-3-030-31589-4_9 